\title{
Humoral immune response of pigs, Sus scrofa domesticus, upon repeated exposure to blood-feeding by Ornithodoros turicata Duges (Ixodida: Argasidae)
}

Hee J. Kim ${ }^{1}$, Aparna Krishnavajhala ${ }^{2}$, Brittany A. Armstrong ${ }^{2,3}$, Adalberto A. Pérez de León ${ }^{4 *}$, Serhii Filatov ${ }^{5}$, Pete D. Teel ${ }^{1}$ and Job E. Lopez ${ }^{2,3^{*}}$

\begin{abstract}
Background: Ornithodoros turicata is an important vector of both human and veterinary pathogens. One primary concern is the global spread of African swine fever virus and the risk of its re-emergence in the Americas through potential transmission by 0 . turicata to domestic pigs and feral swine. Moreover, in Texas, African warthogs were introduced into the state for hunting purposes and evidence exists that they are reproducing and have spread to three counties in the state. Consequently, it is imperative to develop strategies to evaluate exposure of feral pigs and African warthogs to O. turicata.
\end{abstract}

Results: We report the development of an animal model to evaluate serological responses of pigs to 0 . turicata salivary proteins after three exposures to tick feeding. Serological responses were assessed for $\sim 120$ days by enzymelinked immunosorbent assay and immunoblotting using salivary gland extracts from O. turicata.

Conclusions: Our findings indicate that domestic pigs seroconverted to $O$. turicata salivary antigens that is foundational toward the development of a diagnostic assay to improve soft tick surveillance efforts.

Keywords: Ornithodoros, Western blotting, Enzyme-linked immunosorbent assay, Vector-host interactions

\section{Background}

Ornithodoros turicata Duges is a nidicolous, cavity dwelling argasid tick found in the southwestern USA, Mexico, and Florida [1-3]. This soft tick species is recognized as a vector of human relapsing fever, caused by the spirochete Borrelia turicatae $[4,5]$. Additionally, laboratory studies documented the potential role of O. turicata as a vector of other pathogens including African swine fever

\footnotetext{
*Correspondence: beto.perezdeleon@usda.gov; job.lopez@bcm.edu

${ }^{2}$ Department of Pediatrics, National School of Tropical Medicine, Baylor

College of Medicine, Houston, TX, USA

${ }^{4}$ Knipling-Bushland U.S. Livestock Insects Research Laboratory

and Veterinary Pest Genomics Center, United States Department

of Agriculture, Agricultural Research Service, Kerrville, TX, USA

Full list of author information is available at the end of the article
}

virus (ASFV) [6]. ASFV is a highly contagious pathogen of swine and recognized as a select agent by the USDA. First discovered in 1920 in Kenya, ASFV was found to have a sylvatic cycle that principally involves two species of African warthogs, Phacochoerus aethiopicus Pallas and Phacochoerus africanus Gmelin (both Artiodactyla: Suidae) [7]. These species also serve as hosts for O. moubata, the argasid vector. ASFV moved into Spain, in the 1960s and remained enzootic in the region sustained in part by the vector O. erraticus, until it was eradicated [8]. Recent expansions of ASF through the Caucasus region, into Europe, and most recently to Asia have increased concerns of a global threat to the swine industry [9]. Importantly, in the USA, African warthogs were imported into Texas as wild game. Recently, the animals have escaped 
and been spotted in three counties within the state (Fig. 1) and are reproducing. This signifies an ecological setting for the emergence of ASFV in the USA.

The sylvatic cycle of ASFV in Africa produces little to no clinical manifestations among infected warthogs, or the limited feral swine that recover from infection $[9,10]$. However, both ASFV-infected vectors and the sylvatic hosts can transmit ASFV to domestic swine, Sus scrofa domesticus Erxleben (Artiodactyla: Suidae) populations with devastating consequences [9]. Infected swine shed ASFV directly and mortality rates approach $100 \%$ by acute hemorrhagic fever [10]. Meat and animal by-products from infected swine can provide sources of spread through global trade and human transport and a possible source of introduction to the western Hemisphere [11]. The USA is the world's third-largest producer of pork products. In 2015, the USA produced more than 110 metric tons of pork products valued at $\$ 22$ billion and supporting 550,000 USA jobs [12, 13]. Therefore, an introduction of ASFV to the USA could induce severe economic consequences and risk potential establishment in O. turicata populations. The global spread of ASFV poses the risk of its re-emergence in the Americas, and the potential transmission by O. turicata to domestic pigs (Sus scrofa domesticus) and feral swine (Sus scrofa scrofa).

The host range of $O$. turicata remains to be fully understood. Larvae, nymphs and adults of $O$. turicata acquire a blood meal rapidly as compared to hard ticks [14], and are rarely discovered feeding on hosts. The host list includes many diverse animals when considering the extensive fauna frequenting cavity environments where O. turicata has been collected [2]. Recent serological evidence of sampled feral swine indicated the animals were exposed to $B$. turicatae, providing indirect evidence of O. turicata blood-feeding on feral swine in Texas [15].

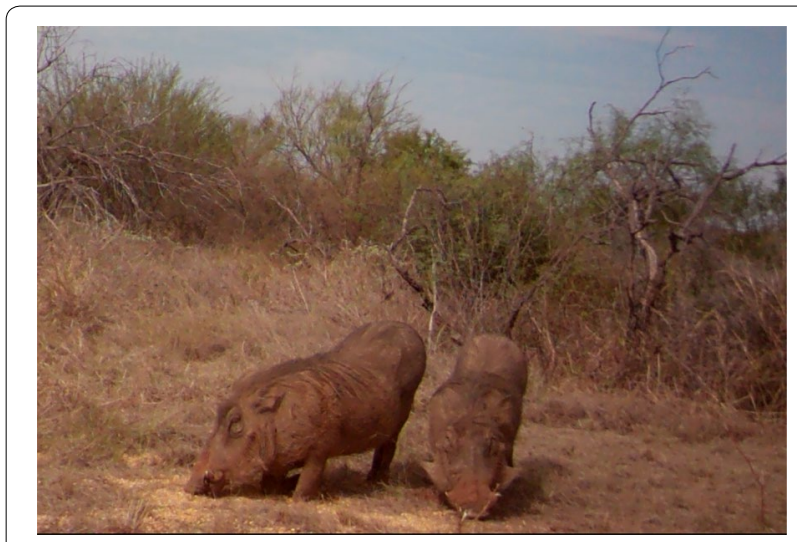

Fig. 1 Photographic images of two African warthogs taken using a Moultrie game camera. Images were taken in La Salle County, Texas, USA
Additionally, photographic and field evidence confirmed feral swine visitations to O. turicata infested caves and rodent burrows. Parasitism of feral swine moving across the USA-Mexico transboundary region provides a potential pathway for the emergence of ASFV in the USA [43].

Argasid ticks, including O. turicata, may be found in peridomestic and domestic settings $[1,16]$, with their habitats overlapping that of feral swine. However, the extent of feral swine exposure to O. turicata in the USA is unknown. The omnivorous behavior, habitat association, and landscape usage of feral swine suggest there are opportunities for $O$. turicata-feral swine interactions [17-20]. Importantly, direct interaction between feral swine and domestic swine occurs $[19,21]$, which poses a concern for the spread of emerging pathogens in the USA. Therefore, it is important to develop approaches that will aid in surveillance efforts.

A knowledge gap exists in the antibody response generated in pigs after exposure to blood-feeding by $O$. turicata. Defining the humoral response against tick salivary proteins will facilitate surveillance studies to estimate exposure of feral swine to $O$. turicata feeding. In this study, we documented the feeding success of O. turicata on domestic pigs and evaluated antibody responses against tick salivary proteins. Animals were exposed to 100 ticks in each of the three challenges. IgG responses were assessed by enzyme-linked immunosorbent assay (ELISA) and immunoblotting to salivary gland extracts (SGE) from dissected ticks. Our findings indicated that domestic pigs seroconverted to $O$. turicata salivary proteins. These results suggest that a serological assay could be implemented for surveillance studies to determine the exposure of domestic pigs and feral swine to O. turicata.

\section{Methods}

\section{Ornithodoros turicata colony}

Adult and late-instar O. turicata nymphs used in this study originated from specimens collected in a natural cavern in Travis County, Texas, USA, in 1992 and are maintained in colony at the Tick Research Laboratory at Texas A\&M AgriLife Research, College Station, TX, USA. Ticks were reared on young cockerels (Gallus gallus) as blood-meal host, and maintained under a $14: 10$ h (light:dark) photoperiod, temperature of $25.0 \pm 3.0^{\circ} \mathrm{C}$, and relative humidity of $80-85 \%$. Prior to feeding cohorts of $O$. turicata on pigs, they were starved for seven months.

\section{Host preparation}

Four weaned domestic pigs (S. s. domesticus) weighing $15-20 \mathrm{~kg}$ were acquired from a commercial swine producer. The pigs were maintained at the Texas A\&M University Veterinary Medical Research Park for the 
duration of the study in accordance with IACUCapproved AUP No. 2015-0089. This facility was specifically designed to maintain an ectoparasite free environment other than the ticks used in the study. Pigs were quarantined for two weeks during which they received standard veterinary preventative treatment in accordance with operating procedures of the research facility. Pigs underwent two positive reinforcement training sessions for acclimation to a sling apparatus. This method facilitated tick feeding and venous blood collection from the pigs.

Table 1 Summary of the experimental timeline and procedures

\begin{tabular}{ll}
\hline Experimental day & Procedure \\
\hline 01 & Pre-challenge blood sample collection \\
08 & Tick challenge \#1 \\
21 & Post-challenge blood sample \#1 \\
22 & Tick challenge \#2 \\
35 & Post-challenge blood sample \#2 \\
36 & Tick challenge \#3 \\
49 & Post-challenge blood sample \#3 \\
56 & Post-challenge blood sample \#4 \\
63 & Post-challenge blood sample \#5 \\
70 & Post-challenge blood sample \#6 \\
98 & Post-challenge blood sample \#7 \\
126 & Post-challenge blood sample \#8 \\
\hline
\end{tabular}

\section{Tick challenge and blood collection}

Prior to feeding O. turicata on pigs, a pre-challenge serum sample was obtained from each animal. Ticks were fed three times on pigs in 2-week intervals (Table 1). Prior to each tick feeding, a blood sample was obtained from each animal. After the third tick feeding, a blood sample was collected from each animal weekly for four weeks. The final two blood samples were collected 28 days apart (Table 1). For each tick feeding, 100 unfed ticks that had completed four molts (adult and/or late-instar nymphs) were placed in a feeding chamber then randomly assigned to a pig subject. Feeding-chamber design was adapted from previous experiments where the chambers were constructed by removing the bottom of a $250 \mathrm{ml}$ wide-mouth Nalgene bottle (Thermo Fisher Scientific, Waltham, MA, USA) to $4.5 \mathrm{~cm}$ from the top and sealing it with fabric having a mesh size of $2 \mathrm{~mm}$ through which the ticks could feed [22, 23] (Fig. 2). Feeding chambers were secured onto the backs of the pig subjects for $60 \mathrm{~min}$ using $3 \mathrm{M}$ VetRap (3M, Oakdale, MN, USA).

Ten $\mathrm{ml}$ blood samples from each pig were collected over the course of the study (Table 1 ). The pre-challenge blood sample collected served as the control (baseline). The collected blood samples were allowed to clot at room temperature and centrifuged using a Variseal Model Vs6c centrifuge (Vulcan Tech, New York, NY, USA) at a $600 \times g$ for $10 \mathrm{~min}$. The isolated serum samples were stored at $-20^{\circ} \mathrm{C}$ until used for analyses.
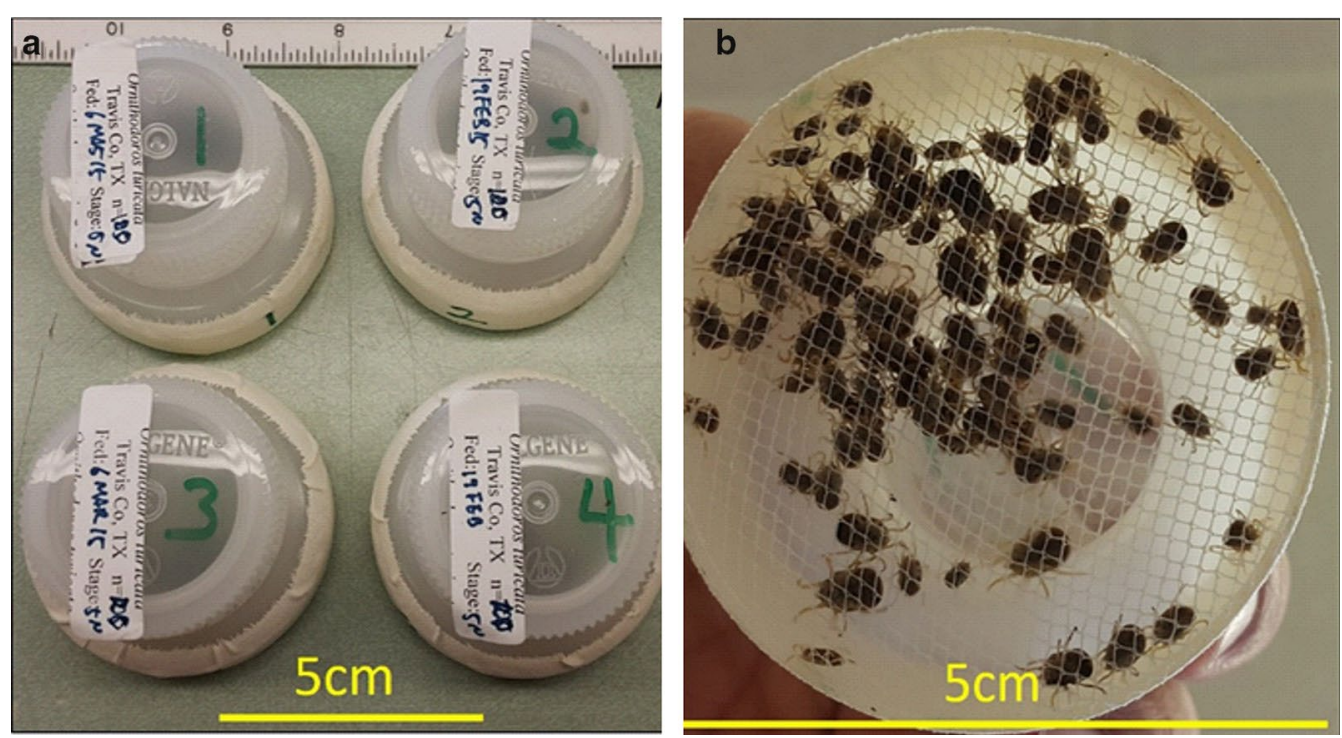

Fig. 2 Feeding chambers used for Ornithodoros turicata challenges. One hundred O. turicata were fed on each pig. Ticks were placed in one of four feeding chambers (a) then randomly assigned to each pig subject. The feeding chamber was sealed with fabric (mesh size $2 \mathrm{~mm}$ ) (b), through which the ticks could feed. Scale-bars are shown at the bottom of each image 


\section{Preparation of tick SGE}

We used SGE as the antigen to assess pig serological responses. Dissected ticks were flat (unfed) late stage nymphs and were reared similar to ticks used for parasitizing pigs. Also, SGE were generated using the modified methods derived from Canals et al. [24]. Each $O$. turicata specimen was placed into phosphate-buffered saline (PBS) with $5 \mathrm{mM}$ magnesium chloride $\left(\mathrm{MgCl}_{2}\right)$ and dissected using an Axio Stemi microscope (Zeiss, Munich, Germany). Salivary glands were removed using forceps and washed with PBS and $5 \mathrm{mM}$ of $\mathrm{MgCl}_{2}$. Salivary glands were placed in $1.5 \mathrm{ml}$ tube containing $100 \mu \mathrm{l}$ of PBS and $5 \mathrm{mM}$ of $\mathrm{MgCl}_{2}$, homogenized using a polypropylene pestle (Bel-Art Products, Wayne, NJ, USA), and centrifuged at $10,000 \times g$ for $5 \mathrm{~min}$. Protein concentration of SGE supernatants were determined using Epoch Microplate Spectrophotometer and Gen5 Data Analysis software version 2.00.18 (BioTek, Winooski, VT, USA) with bovine serum albumin (Bio-Rad, Hercules, CA, USA) as a standard. SGE supernatants were stored at $-4{ }^{\circ} \mathrm{C}$ until needed.

\section{Enzyme-linked immunosorbent assay (ELISA)}

ELISA using SGE was performed to evaluate serological responses over the duration of the study and to determine endpoint titers. Pre- and post-tick challenge serum samples were compared for each animal. For all assays, 96-well flat bottom Immulon $2 \mathrm{HB}$ plates (Thermo Electron, Milford, MA, USA) were coated with $100 \mu \mathrm{l}$ of coating buffer with $1 \mu \mathrm{g}$ of SGE protein per well and incubated overnight at $4{ }^{\circ} \mathrm{C}$. Plates were washed three times with PBS Tween-20 ( $1 \times$ PBS, 0.05\% Tween-20). Each plate was blocked using ELISA diluent (PBS, 0.5\% horse serum, $0.05 \%$ Tween-20, 0.001\% dextran sulfate) at $100 \mu \mathrm{l}$ per well and incubated for $1 \mathrm{~h}$ at room temperature. Plates were washed three times, $100 \mu \mathrm{l}$ of pig sera from tick challenges were added to wells at a dilution of $1: 100$, and plates were incubated at room temperature for one hour. Each plate was washed three times as stated above, and $100 \mu \mathrm{l}$ of the secondary antibody, anti-pig IgG Fc-HRP (Thermo Fisher Scientific, Waltham, MA, USA), was added to each well at 1:5000 dilution. After an hour of incubation at room temperature, each plate was washed three times, and $100 \mu$ ELISA HRP substrate was added to each well and incubated at room temperature for $15 \mathrm{~min}$. The optical density of each plate was evaluated at $405 \mathrm{~nm}$ absorbance using the Epoch Microplate Spectrophotometer and Gen5 Data Analysis software version 2.00.18 (BioTek, Winooski, VT, USA).

To determine endpoint titers, ELISA was performed using serum samples at a 1:100 to $1: 512,000$ dilution. Pre-challenge serum samples diluted 1:100 were also used. All samples were tested in triplicate and means and standard deviations determined. Samples were considered statistically significant if their mean optical density was more than three times the standard deviation of the mean of the pre-tick challenge serum sample, as previously reported $[25,26]$.

\section{Sodium dodecyl sulfate polyacrylamide gel electrophoresis (SDS-PAGE) and immunoblotting} Proteins were separated by SDS-PAGE and immunoblotting was performed to determine seroconversion, as described [27]. Three $\mu \mathrm{g}$ of SGE supernatant was electrophoresed on Mini-Protean TGX precast gels (Bio-Rad) at 80 volts for $90 \mathrm{~min}$. Proteins were transferred to polyvinylidene fluoride (PVDF) membranes (Millipore, Billerica, MA, USA) using 100 volts for $60 \mathrm{~min}$ in a Mini Trans Blot system (Bio-Rad). PVDF membranes were blocked overnight with I-Block Protein-Based Blocking Reagent (Life Technologies, Grand Island, NY, USA). Immunoblots were probed with pig serum samples as primary antibodies at a 1:200 dilution for one hour. Membranes were washed with I-Block for one hour and anti-pig IgG-HRP (Life Technologies) was used as the secondary antibody at a 1:4000 dilution. Serological reactivity was determined with the Amersham Enhanced Chemiluminescence (ECL) Western Blotting System (GE Healthcare Bio-Science Corp., Piscataway, NJ, USA).

\section{Statistics}

The statistical program JMP Pro 12 statistical software (SAS Co., Cary, NC, USA) was used. ANOVA and a Tukey's honest significant difference (HSD) post-hoc test based on an alpha level of 0.05 were performed for all pairwise combinations to determine significant differences in total tick fed and post-blood-feeding weight increase between challenges, feeding chamber, and pig subjects.

\section{Results}

Evaluation of tick feeding

Ornithodoros turicata readily fed on pigs. For tick cohorts that fed on the four animals, we observed between a 2.01to 5.85 -fold change in weight after feeding (Fig. 3). The proportion of ticks that fed, and the weight increase per cohort were similar among the four pigs used in these experiments $\left(F_{(3,8)}=1.556 ; P=0.2739\right.$ for total ticks fed, and $F_{(3,8)}=0.9568 ; P=0.4584$ for weight increase per cohort). Similarly, the fraction of ticks that fed, and the weight increase per cohort were not significantly different according to feeding chamber $\left(F_{(3,8)}=1.8209 ; P=0.2214\right.$ for total tick fed, and $F_{(3,8)}=0.20901 ; P=0.8873$ for weight increase per cohort). The percent weight increase was not significantly different based on challenges $\left(F_{(2,}\right.$ 


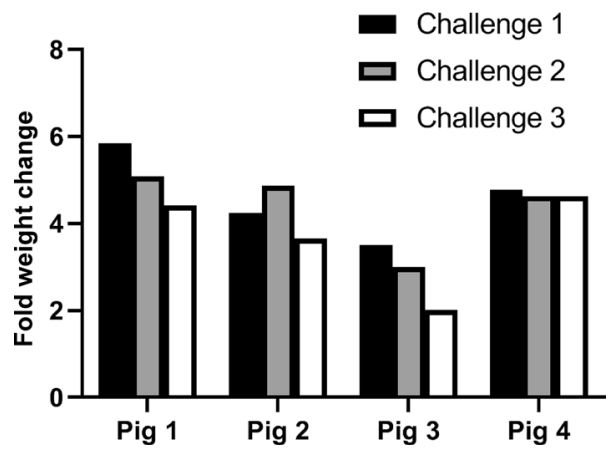

Fig. 3 Fold weight change after feeding cohorts of 100 ticks on a given animal. Change in weight was determined by weighing pre- and post-fed tick cohorts. Shown are challenge 1 (black fill), 2 (grey fill) and 3 (white)

9) $=3.7277 ; P=0.0662)$. However, the total number of ticks fed significantly differed between challenge dates $\left(F_{(2,9)}=5.1758 ; P=0.0319\right)$. Specifically, total ticks that fed during challenge 3 were significantly different from those of challenge 1 (Tukey's HSD $P=0.0261$ ). A proportional decrease in ticks fed of $14 \%, 14 \%, 16 \%$ and $7 \%$ for pigs 1 to 4 , respectively, was noted between the first and third challenges. These findings suggest that repeated tick exposure to pigs may impact tick feeding success.

\section{Pig serological responses following 0 . turicata feeding}

To evaluate serological responses to tick salivary proteins, we dissected intact salivary glands from O. turicata (Fig. 4) and used them to generate SGE. Within 13 days after the first tick challenge (day 21 of the experimental design, Table 1), ELISA assays detected statistically significant $(P \leq 0.003)$ IgG responses from all pigs compared to the respective mean pre-challenge serum samples from each pig (Fig. 5a-d). Elevated IgG responses were detectable for a majority of the study (Fig. 5a-d). Pig 1 generated the most prolonged IgG response for the duration of the study (Fig. 5a) with statistically significant $(P \leq 0.003)$ detection occurring with the final serum sample tested. IgG responses of pig 2 were above the pre-challenge serum sample cut-off for 27 days after the third tick challenge, after which antibody responses were undetectable (Fig. $5 \mathrm{~b}$ ). Pig 3 generated a statistically significant $(P \leq 0.003)$ IgG response for 34 days after the third tick challenge (Fig. 5c). Pig 4 generated a prolonged IgG response that was above the pre-challenge cut-off until day 98 (Fig. 5d). At day 126, pig 4's serological response rose above the pre-challenge cut-off. Endpoint titers were determined using post-challenge sera with the highest OD reading. Pig 2 generated the strongest response with a titer of $1: 16,000$, while pig 4 had the weakest response with a titer of 1:4000.

The antigenic profile detected in pig serum samples was further assessed by immunoblotting using SGE from O. turicata (Fig. 6). Reactivity using serum samples prior to tick challenge was compared to serum samples collected 13 days after the third tick feeding, indicating the antigenicity of salivary secretions. Salivary antigens with molecular masses of $\sim 15$ to $\sim 100 \mathrm{kDa}$ were identified. All the pigs showed a strong IgG response to salivary proteins with a molecular weight of $\sim 25 \mathrm{kDa}$. These results indicated that $O$. turicata salivary secretions were antigenic in domestic pigs.
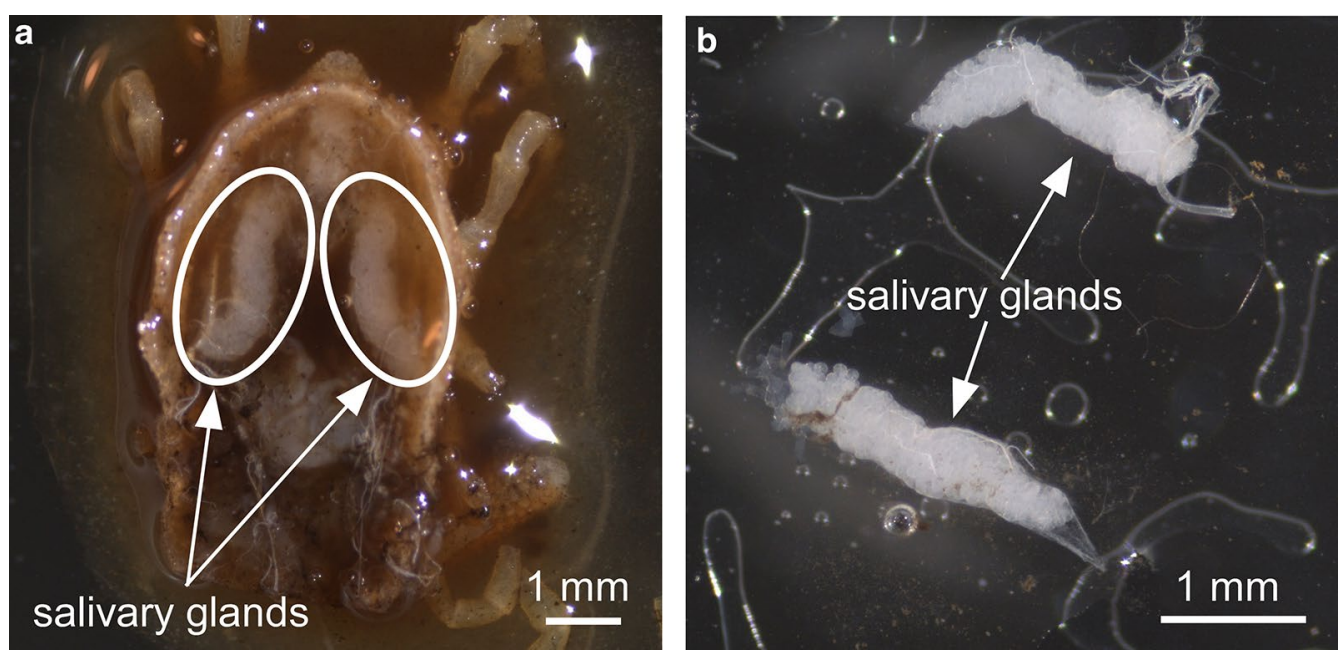

Fig. 4 Dissection of Ornithodoros turicata salivary glands. Ticks were dissected, removing the midgut, which exposed the salivary glands (a). Salivary gland sets were excised and rinsed to remove residual midgut content (b). Scale-bars are shown in the bottom left of each image 

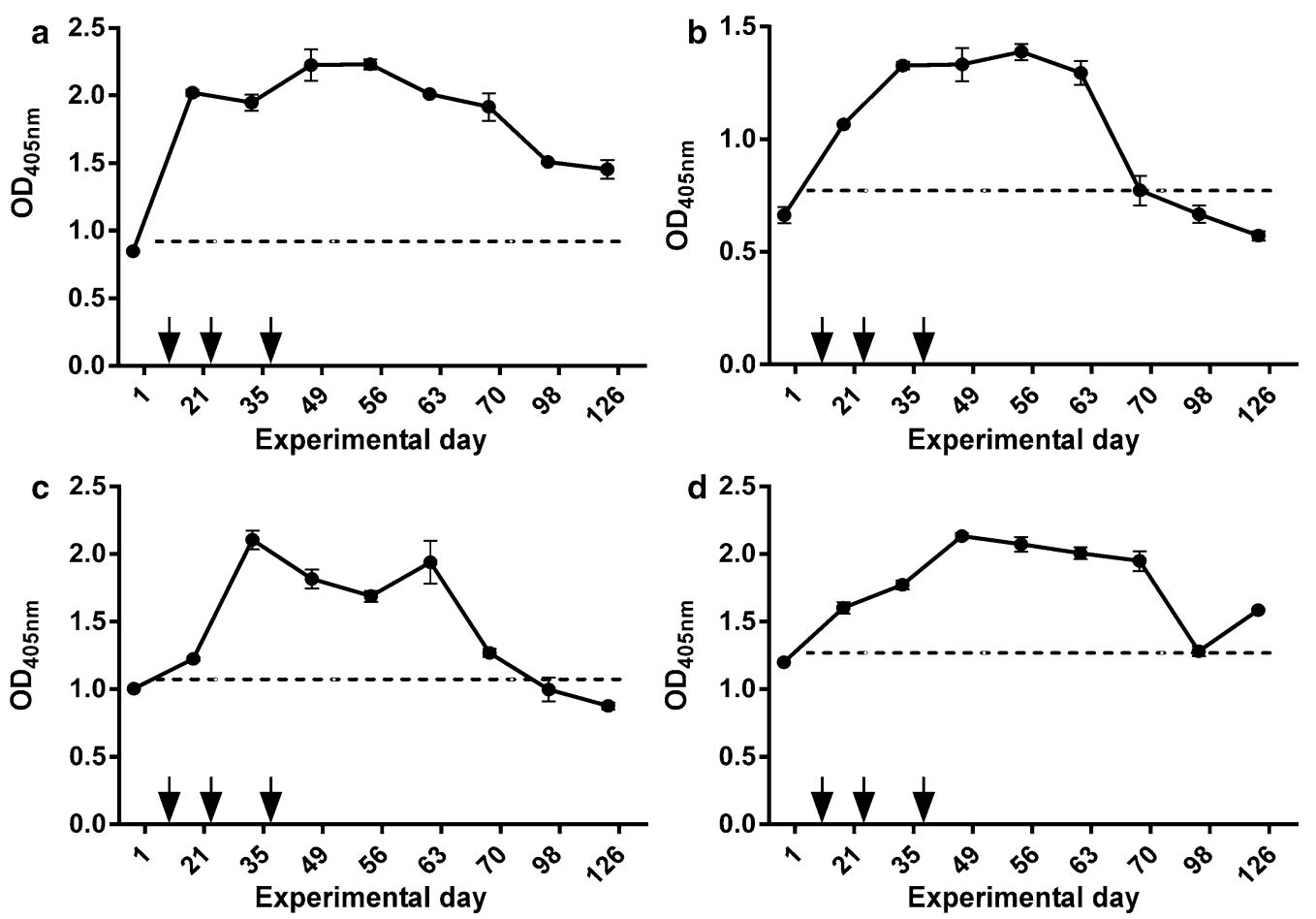

Fig. 5 ELISA assessment of temporal serological responses to tick SGE. Serum samples from animals 1 (a), 2 (b), 3 (c) and 4 (d) were evaluated prior to (day 1 ) and for 90 days after the third tick challenge. Arrows denote the days of tick feedings. A sample was considered statistically significant $(P \leq 0.003)$ if their mean optical density was more than three times the standard deviation of the mean of the pre-tick challenge serum sample. This threshold is represented by a dotted line

\section{Discussion}

Our study reports serological responses of pigs to $O$. turicata salivary antigens after repeatedly exposing the animals to the ticks. The animals seroconverted to O. turicata salivary proteins that ranged from $\sim 15$ to $100 \mathrm{kDa}$ and this was sustained between 27 to 90 days after the third tick challenge. In previous work, humoral response of rabbits was evaluated after $O$. turicata feeding [28]. Wozniak et al. [28] reported an increase of IgG production in rabbits that were challenged with several Ornithodoros species. They fed $O$. turicata, O. talaje and O. coriaceus on rabbits biweekly and evaluated IgG responses to SGE by ELISA and immunoblotting. Each feeding involved 150 ticks from each Ornithodoros species, and the rabbits were exposed four times. Salivary gland proteins recognized by the rabbit antibodies ranged from $\sim 15$ to $\sim 130 \mathrm{kDa}$, and endpoint titers were $\sim 1: 5120$. However, the longevity of IgG responses after the fourth tick challenge were not reported. Similar to our findings, rabbits also developed serological responses to a salivary protein of $\sim 25 \mathrm{kDa}$ [28], but it is unknown whether these proteins are the same.
When we evaluated serum samples of each pig, differences between the serological assays were observed. For example, while serological responses from each animal were similar when assessed by ELISA, immunoblotting indicated differing reactivity between animals. Specifically, when we tested serum samples collected 13 days after the third challenge, pig 1 reacted with more antigens from SGE compared to the other animals. While not determined in our study, the haplotypic diversity of pig 1 may have affected the antigen repertoire recognized by this animal.

After the tick third challenge, we observed a weight loss between $O$. turicata ticks that fed compared to cohorts from the first two feedings due to fewer ticks feeding. A decline in successful tick feeding on repeatedly exposed animals is an indicator of acquired immunity against arthropods [29-32]. Riek et al. [33] reported hypersensitivity to Rhipicephalus (Boophilus) microplus salivary secretion elicited by heavy tick infestation, which resulted in histological changes of the skin at the site of attachment of two species of cattle, Bos taurus L. (Artiodactyla: Bovidae) and Bos indicus L. Similarly, Szabó \& Bechara [34] reported that repeat exposures to 

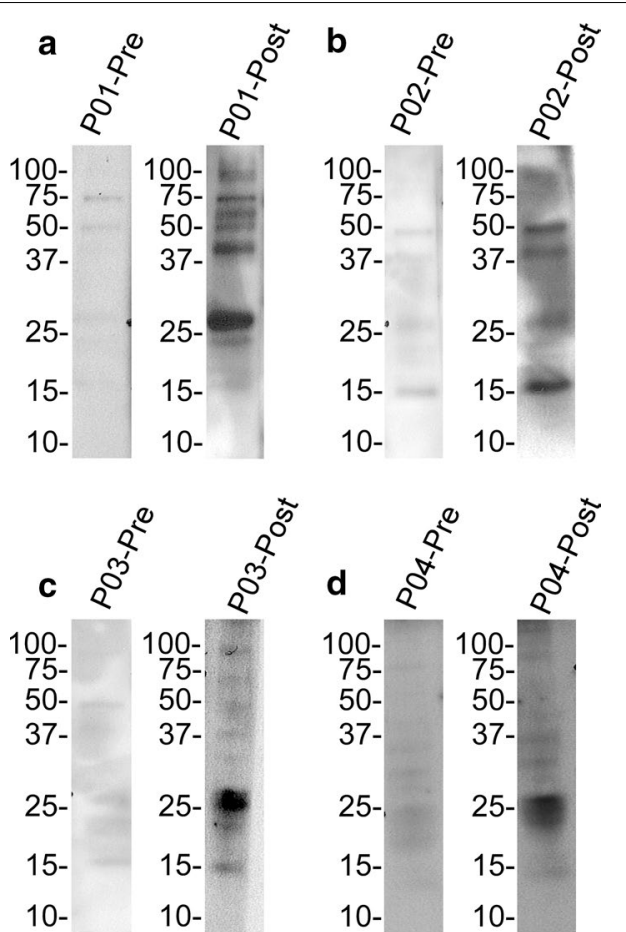

Fig. 6 Immunoblot analysis of serum samples from pigs fed upon by Ornithodoros turicata. Pre- and post-exposure serum samples from animal 1 (a), 2 (b), 3 (c) and 4 (d) were used to evaluate seroconversion. Serological reactivity to a $\sim 25 \mathrm{kDa}$ protein was observed from the four animals. Molecular masses are indicated on the left of each immunoblot

Rhipicephalus sanguineus (s.l.) Latreille (Ixodida: Ixodidae) elicited strong skin inflammatory responses from both dogs and guinea pigs. These studies evaluated successful feeding of ixodid ticks, which lay cement, attach for days, and regurgitate midgut content. Moreover, ixodid salivary and midgut proteins are antigenic and have been targeted to interrupt tick feeding [35]. In comparison, $O$. turicata engorges within minutes of attachment, and it remains unknown if midgut content is regurgitated and an immune response induced, which could impact feeding success. Moreover, while salivary secretions are antigenic in Ornithodoros species, it is unclear as to whether the immune response generated against the proteins would impact subsequent tick feedings.

Numerous species of ixodid ticks feed on feral swine in Texas [15], however less is known about interactions between argasids and feral swine because they are rapid feeders that are rarely found attached to the host. Feral swine populations have become a serious threat throughout the southern USA, overlapping the known Florida and southwestern distributions of O. turicata [36]. Our studies suggest that feral swine could potentially serve as sentinels to detect the presence of $O$. turicata through serologic surveillance. This has been demonstrated in previous work demonstrating the antigenicity of salivary secretions from $O$. erraticus and $O$. moubata in swine $[24,37]$. This approach was also used to measure tick exposure in swine populations in the Iberian Peninsula, Sardinia, and Madagascar as part of assessing ASFV epidemiology and progress toward disease control and elimination [38-41]. Consequently, to improve surveillance efforts, it is important to develop an accurate molecular assay to differentiate exposure of feral swine to Ornithodoros species and ixodid ticks. With the availability of the O. turicata salivary gland transcriptome [42], future proteomic work will identify the tick salivary antigens recognized by the vertebrate immune response. This will be an important first step toward the development of a specific assay to evaluate the exposure of domestic and wild pigs to $O$. turicata salivary proteins.

\section{Conclusions}

This study describes a successful animal model to study molecular interactions between Ornithodoros ticks and pigs that could aid in further development of methods to study soft tick ecology, as well as in establishing early detection and prevention of ASF entry into the USA through wildlife.

\section{Abbreviations}

ASF: African swine fever; ASFV: African swine fever virus; ELISA: enzyme-linked immunosorbent assay; SGE: salivary gland extract; IACUC: Institutional Animal Care and Use Committee; AUP: animal use protocol; PBS: phosphate-buffered saline; HRP: horseradish peroxidase; ANOVA: analysis of variance; HSD: honest significant difference.

\section{Acknowledgements}

We thank Texas Parks and Wildlife for access to wildlife management areas and photographs of African warthogs.

\section{Authors' contributions}

HJK developed the project, performed experiments, analyzed data and wrote the manuscript. AK and BAA performed ELISA and immunoblotting experiments and analyzed data. AAPL participated in experimental design, SF participated in performing tick feedings on pigs, PDT participated in the experimental design, tick feedings, data interpretation and writing the manuscript. JEL participated in the experimental design, tick feedings, ELISA and immunoblotting data interpretation, and writing the manuscript. All authors read and approved the final manuscript.

\section{Funding}

This project was funded in part by the United States Department of Agriculture, Agricultural Research Service, (USDA-ARS) through Cooperative Agreement Number 59-3094-5-001, by the Cooperative Threat Reduction (CTR) Cooperative Biological Engagement Program (CBEP) (Agreement No. 09-001-10841), by the USA Army Medical Department (AMEDD) Long Term Health Education and Training program for FY 2015-2017, and by Texas A\&M AgriLife Research. This study was also supported by funds from the National School of Tropical Medicine at Baylor College of Medicine. Its contents are solely the responsibility of the authors and do not necessarily represent the official views of the USDS-ARS, Texas A\&M AgriLife Research, or AMEDD. USDA is an equal opportunity provider and employer. 


\section{Availability of data and materials}

The datasets generated in this study are available upon request.

\section{Ethics approval and consent to participate}

Pigs studies were performed at Texas A\&M University Veterinary Medical Research Park in accordance with IACUC-approval, AUP No. 2015-0089.

\section{Consent for publication}

Not applicable.

\section{Competing interests}

The authors declare that they have no competing interests.

\section{Author details}

1 Department of Entomology, Texas A\&M AgriLife Research, College Station, TX, USA. ${ }^{2}$ Department of Pediatrics, National School of Tropical Medicine, Baylor College of Medicine, Houston, TX, USA. ${ }^{3}$ Department of Molecular Virology and Microbiology, Baylor College of Medicine, Houston, TX, USA. ${ }^{4}$ Knipling-Bushland U.S. Livestock Insects Research Laboratory and Veterinary Pest Genomics Center, United States Department of Agriculture, Agricultural Research Service, Kerrville, TX, USA. ${ }^{5}$ Laboratory of Virology, National Scientific Center, "Institute of Experimental and Clinical Veterinary Medicine", Kharkiv, Ukraine.

Received: 7 July 2019 Accepted: 3 February 2020

Published online: 12 February 2020

\section{References}

1. Cooley RA, Kohls GM. The Agarasidae of North America, Central America, and Cuba., the American midland naturalist, Monography no. 1 Notre Dame: The University Press; 1944. p. 1-152.

2. Donaldson TG, Pérez de León AA, Li Al, Castro-Arellano I, Wozniak E, Boyle WK, et al. Assessment of the geographic distribution of Ornithodoros turicata (Argasidae): climate variation and host diversity. PLoS Negl Trop Dis. 2016;10:e0004383.

3. Felsenfeld $\mathrm{O}$. The problem of relapsing fever in the Americas. IMS. 1973:42:7-10.

4. Krishnavajhala A, Armstrong BA, Lopez JE. Vector competence of geographical populations of Ornithodoros turicata for the tick-borne relapsing fever spirochete Borrelia turicatae. Appl Environ Microbiol. 2018;84:e01505-18.

5. Schwan TG, Raffel SJ, Schrumpf ME, Policastro PF, Rawlings JA, Lane RS, et al. Phylogenetic analysis of the spirochetes Borrelia parkeri and Borrelia turicatae and the potential for tick-borne relapsing fever in Florida. J Clin Microbiol. 2005;43:3851-9.

6. Hess WR, Endris RG, Haslett TM, Monahan MJ, McCoy JP. Potential arthropod vectors of African swine fever virus in North America and the Caribbean basin. Vet Parasitol. 1987;26:145-55.

7. Montgomery RE. On a form of swine fever occurring in British East Africa (Kenya Colony). J Comp Pathol Ther. 1921;34:159-91.

8. Bech-Nielsen S, Fernandez J, Martinez-Pereda F, Espinosa J, Bonilla QP Sanchez-Vizcaino J. A case study of an outbreak of African swine fever in Spain. Br Vet J. 1995;151:203-14.

9. Costard S, Wieland B, de Glanville W, Jori F, Rowlands R, Vosloo W, et al. African swine fever: how can global spread be prevented? Philos Trans $R$ Soc Lond B Biol Sci. 2009;364:2683-96.

10. Plowright W, Thomson G, Neser J. African swine fever. Infectious diseases of livestock, with special reference to southern Africa. Cape Town: Oxford University Press; 1994

11. Herrera-Ibata DM, Martinez-Lopez B, Quijada D, Burton K, Mur L. Quantitative approach for the risk assessment of African swine fever and classical swine fever introduction into the United States through legal imports of pigs and swine products. PLOS ONE. 2017;12:e0182850.

12. National Pork Producers Council. Pork facts: national pork producers council. 2015. http://nppc.org/pork-facts/. Accessed 10 Mar 2016.

13. USDA. Livestock and poultry: world markets and trade: foreign agricultural service/USDA office of global analysis. USDA; 2016. https:// downloads.usda.library.cornell.edu/usda-esmis/files/73666448x/0r967 405p/9s1616627/livestock-poultry-ma-10-12-2016.pdf, https://www. fas.usda.gov/. Accessed 15 Mar 2016.

14. Sonenshine DE, Roe RM. Biology of ticks. 2nd ed. New York: Oxford University Press; 2014.

15. Sanders DM, Schuster AL, McCardle PW, Strey OF, Blankenship TL, Teel PD. Ixodid ticks associated with feral swine in Texas. J Vector Ecol. 2013;38:361-73.

16. Lopez JE, Krishnavahjala A, Garcia MN, Bermudez SE. Tick-borne relapsing fever spirochetes in the Americas. Vet Sci. 2016;3:1-18.

17. Coombs D, Springer M. Parasites of feral pig X European wild boar hybrids in southern Texas. J Wildl Dis. 1974;10:436.

18. Cushman J, Tierney TA, Hinds JM. Variable effects of feral pig disturbances on native and exotic plants in a California grassland. Ecol Appl. 2004; 14:1746-56.

19. Wyckoff AC, Henke SE, Campbell TA, Hewitt DG, VerCauteren KC. Feral swine contact with domestic swine: a serologic survey and assessment of potential for disease transmission. J Wildl Dis. 2009;45:422-9.

20. Campbell TA, Long DB. Activity patterns of wild boars (Sus scrofa) in southern Texas. Southwest Nat. 2010:55:564-7.

21. Witmer GW, Sanders RB, Taft AC. Feral swine-are they a disease theat to livestock in the United States? In: 10th Wildlife damage management conference. 2003. Lincoln, NE, USA: USDA National Wildlife Research Center-Staff Publications; 2003.

22. Kim HJ, Filatov S, Lopez JE, Pérez de León AA, Teel PD. Blood feeding of Ornithodoros turicata larvae using an artificial membrane system. Med Vet Entomol. 2017;31:230-3.

23. Zheng H, Li AY, Teel PD, Pérez de León AA, Seshu J, Liu J. Biological and physiological characterization of in vitro blood feeding in nymph and adult stages of Ornithodoros turicata (Acari: Argasidae). J Insect Physiol. 2015;75:73-9.

24. Canals A, Oleaga A, Pérez R, Domínguez J, Encinas A, Sánchez-Vizcaino J. Evaluation of an enzyme-linked immunosorbent assay to detect specific antibodies in pigs infested with the tick Ornithodoros erraticus (Argasidae). Vet Parasitol. 1990;37:145-53.

25. Lopez JE, Porcella SF, Schrumpf ME, Raffel SJ, Hammer CH, Zhao M, et al. Identification of conserved antigens for early serodiagnosis of relapsing fever Borrelia. Microbiology. 2009;155:2641-51.

26. Sanders DM. Ticks and tick-borne pathogens associated with feral swine in Edwards Plateau and Gulf prairies and marshes ecoregions of Texas. Ph.D. thesis, Texas A\&M University, USA; 2011.

27. Lopez JE, Wilder HK, Boyle W, Drumheller LB, Thornton JA, Willeford $B$, et al. Sequence analysis and serological responses against Borrelia turicatae BipA, a putative species-specific antigen. PLoS Negl Trop Dis. 2013;7:e2454.

28. Wozniak EJ, Butler JF, Zam SG. Evidence of common and genus-specific epitopes on Ornithodoros spp. tick (Acari: Argasidae) salivary proteins. J Med Entomol. 1995;32:484-9.

29. Brossard M, Wikel SK. Tick immunobiology. Parasitology. 2004;129:S161-76.

30. Kazimirova M, Stibraniova I. Tick salivary compounds: their role in modulation of host defences and pathogen transmission. Front Cell Infect Microbiol. 2013;3:43.

31. Wikel SK. Host immunity to ticks. Annu Rev Entomol. 1996;41:1-22.

32. Trager W. Acquired immunity to ticks. J Parasitol. 1939;25:57-81.

33. Riek R. Studies on the reactions of animals to infestation with ticks. VI. Resistance of cattle to infestation with the tick Boophilus microplus (Canestrini). Crop Pasture Sci. 1962;13:532-50.

34. Szabó MPJ, Bechara GH. Sequential histopathology at the Rhipicephalus sanguineus tick feeding site on dogs and guinea pigs. Exp Appl Acarol. 1999;23:915-28.

35. Labuda M, Trimnell AR, Lickova M, Kazimirova M, Davies GM, Lissina $\mathrm{O}$, et al. An antivector vaccine protects against a lethal vector-borne pathogen. PLoS Pathog. 2006;2:e27.

36. Pedersen K, Lutman MW, Bevins SN, Gidlewski T, Deliberto TJ. Consequences associated with the recent range expansion of nonnative feral swine. BioScience. 2014;64:291-9.

37. Baranda JA, Perez-Sanchez R, Oleaga-Perez A, Encinas-Grandes A. Antigens of interest for the diagnosis of parasitism in pigs by Ornithodoros erraticus and Ornithodoros moubata. J Parasitol. 1997;83:831-8. 
38. Boinas F, Ribeiro R, Madeira S, Palma M, de Carvalho IL, Nuncio S, et al. The medical and veterinary role of Ornithodoros erraticus complex ticks (Acari: Ixodida) on the Iberian Peninsula. J Vector Ecol. 2014;39:238-48.

39. Oleaga-Perez A, Perez-Sanchez R, Astigarraga A, Encinas-Grandes A. Detection of pig farms with Ornithodoros erraticus by pig serology. Elimination of non-specific reactions by carbohydrate epitopes of salivary antigens. Vet Parasitol. 1994;52:97-111.

40. Ravaomanana J, Jori F, Vial L, Perez-Sanchez R, Blanco E, Michaud V, et al. Assessment of interactions between African swine fever virus, bushpigs (Potamochoerus larvatus), Ornithodoros ticks and domestic pigs in northwestern Madagascar. Transbound Emerg Dis. 2011;58:247-54.

41. Mur L, Iscaro C, Cocco M, Jurado C, Rolesu S, De Mia GM, et al. Serological surveillance and direct field searching reaffirm the absence of
Ornithodoros erraticus ticks role in African swine fever cycle in Sardinia. Transbound Emerg Dis. 2017;64:1322-8.

42. Bourret TJ, Boyle WK, Zalud AK, Valenzuela JG, Oliveira F, Lopez JE. The relapsing fever spirochete Borrelia turicatae persists in the highly oxidative environment of its soft-bodied tick vector. Cell Microbiol. 2019;21:e12987.

43. Pérez de León AA, Showler A, Stegniy BT, Kucheryavenko RO, Kucheryavenko W, Gerilovych AP, Filatov SV, Li A, Teel PD, McVey S. Soft tick sampling and collection. J Vet Med Biotechnol Biosaf. 2015;1:5-11

\section{Publisher's Note}

Springer Nature remains neutral with regard to jurisdictional claims in published maps and institutional affiliations.
Ready to submit your research? Choose BMC and benefit from:

- fast, convenient online submission

- thorough peer review by experienced researchers in your field

- rapid publication on acceptance

- support for research data, including large and complex data types

- gold Open Access which fosters wider collaboration and increased citations

- maximum visibility for your research: over $100 \mathrm{M}$ website views per year

At BMC, research is always in progress.

Learn more biomedcentral.com/submissions 